\title{
ВОССТАНОВЛЕНИЕ ОСНОВ ГРАЖДАНСКОГО ПРАВА В ПОЛЬШЕ ПОСЛЕ 1989 г. (ВОПРОС ПРАВА СОБСТВЕННОСТИ)
}

\section{1. Вводные замечания}

Гражданское право сопутствует общественному развитию, изменяя своё содержание в ходе эволюции, которую проходит обществ. В этом процессе происходят различные политические и экономические события, с которыми мы сталкиваемся при изучении развития гражданского права. Право развивается эволюционным путём или подвергается потрясениям, таким же как и общество.

1989 год в истории Польши был богат важными событиями. Среди них самое важное - это парламентские выборы в июле, несмотря на то, что это не были вполне демократические выборы (демократические выборы произошли осенью 1991 г.). Переломным моментом в новейшей истории Польши считается 1989 год, который является началом непосредственного перехода Польши к полному суверенитету.

Как правильно отметил А. Стельмаховски ${ }^{1}$, гражданское право в Польше характеризуется чертой, важность которой вполне могут понять поколения, которым дано было пережить войны и изменения политического строя. Этой чертой является прочность его основных институтов. Это особенная ценность, хотя бы потому, что мало таких институтов, которые отличаются продолжением и постоянством принципов. к ним не принадлежит государство, которое несколько раз прекращало своё существование и теряло независимость, а также территориальное самоуправление и общественные организации.

1 A. Stelmachowski, Zarys teorii prawa cywilnego, Warszawa 1998, s. 11. 
В гражданском праве Польши в формальном смысле проходило много изменений, его содержание было предметом различных экспериментов. Несмотря на это, с перспективы прошедших более, чем двадцати лет (с 1989 г.), можно констатировать, что в гражданском праве существует некоторый ценностный стержень, который не поддался давлению доктрины социализма и позволил сохранить элементарные черты гражданского права в 1944-1989 гг. Однако многие классические правовые конструкции были изъяты или деформированы социалистической идеологией. В такой обстановке период так называемой «строевой трансформации» в Польше, начатый после 1989 г. стал также периодом реконструкции многих классических институтов и ценностей аксиологического характера, дающим обоснование для норм гражданского права или в более широком плане - частного права.

Вероятно, что в данном случае надо говорить не о реформе, но о реконструкции и только потом об изменениях, вытекающих из эволюционного развития права в рыночной экономике. Обычно считается, что понятие «реформа» определяет изменения в какой-то системе, которые однако не означают радикального и качественного преобразования этой системы. Понятие «реконструкция» - это восстановление чего-то на основе сохранившихся фрагментов, восстановление чего-то частично уничтоженного. В гражданском праве остался ценностный стержень, который не поддался давлению доктрины социализма. В такой обстановке сохранилась основа, разрешающая процесс восстановления классических институтов гражданского права.

Стоит вспомнить, что ещё в науке гражданского права времён социалистического строя подчёркивалось, что в области унификации и кодификации 1944-1989 гг. использовался подход, а также конструкции французской, немецкой и австрийской правовой науки, т. е. классические институты, действующие в европейских странах капиталистического строя. Их происхождение вытекало из рецепции римского права в Европе в XVII и XVIII вв. Европа тогда усвоила достижения римских юристов и, кроме того, в XIX веке догматические разработки, находящиеся в «Corpus iuris civilis», были развиты и углублены в правовой науке, создавая т. наз. современную романистическую теорию. На основании догматических разработок римского права возникли большие кодификации, такие как Наполеоновский кодекс, а также гражданский австрийский и немецкий кодексы. Римская догматическая система в этих 
кодификациях подвергалась различным изменениям, однако она являлась их основой.

После приобретения Польшей независимости в 1918 году в её границах действовали различные нормы гражданского права. Обращая внимание на основные правовые системы Польши того времени, надо прежде всего указать на то, что на территории бывшего Царства Польского (Польского конгрессового королевства) в принципе действовал Наполеоновский кодекс, на территории аннексированной Россией - русское право, на землях, ранее захваченных Пруссией - немецкое право, на территории, ранее захваченной Австрией вместе с частью Цешинской Силезии - австрийское право, а также на части земель Спиша и Оравы - венгерское право. ${ }^{2}$ После первой мировой войны начались работы, связанные с кодификацией единого для всей страны гражданского законодательства (в целом именуемые унификационными работами). Стечение многих обстоятельств общественного, политического и экономического характера повлияло на то, что эти работы представляли собой очень трудный и сложный процесс. Несмотря на это, в Польше в период между первой и второй мировыми войнами, было унифицировано обязательственное право и в 1933 г. издан Обязательственный кодекс ${ }^{3}$, очень высоко оцененный теоретиками и практиками. В 1934 г. произошла унификация торгового права в форме Торгового кодекса ${ }^{4}$, а в 1936 г. законы о вексельном и чековом праве. ${ }^{5}$ Надо добавить, что ранее были изданы многие, важные для функционирования народного хозяйства правовые акты, такие как: кооперативное право 1920 г., закон об авторском праве и закон о борьбе с недобросовестной конкуренцией 1926 г., право об охране изобретений, образцов и товарных знаков. ${ }^{6}$

Несмотря на большие усилия юридической общественности не удалось унифицировать все подотрасли гражданского права. Не была унифицирована общая часть гражданского права, вещное и наследственное право. В этих областях права по-прежнему действовали правовые положения бывших государств - захватчиков.

2 S. Grzybowski, (w:) S. Grzybowski (red.), System prawa cywilnego. Część ogólna, Wrocław, Warszawa, Kraków 1985, s. 33).

3 Ж(урнал) З(аконов) Речи Посполитой № 82, поз. 598. (Dz.U.R. P. Nr 82, poz. 598).

4 ЖЗ РП № 57, поз. 502. (Dz.U.R. P. Nr 57, poz. 502).

$5 \quad$ ЖЗ РП № 37, поз. 282. (Dz.U.R. P. Nr 37, poz. 282).

6 S. Grzybowski, (w:) S. Grzybowski (red.), System prawa cywilnego. Część ogólna, Wrocław, Warszawa, Kraków 1985, s. 38. 


\section{2. Идеологизация гражданского права в Польше после 1944 г.}

Законоположения государств - захватчиков потеряли законную силу в 1945-1946 гг. После второй мировой войны были возобновлены работы по унификации положений гражданского права, прежде всего с целью его приспособления к радикально изменившимся условиям общественно-политического строя. Пользуясь проектами унификации и достижениями периода между первой и второй мировыми войнами, эти работы были завершены за два года. В 1945-1946 гг. возникли общие положения гражданского права, вещное и наследственное право. По-прежнему действовали акты, унифицированные в период между первой и второй мировыми войнами (Обязательственный кодекс, Торговый кодекс, а также Вексельное и чековое право). Вскоре действующие в такой форме урегулирования в области гражданского права подверглись резкой политической критике, основанной на ошибочных положениях капиталистических общественно-экономических отношений. Не учитывали нужд «государственной социалистической собственности и обобществлённого оборота», а также обстоятельств «единиц общественной экономики», к которым только в очень ограниченном объёме могли применяться положения гражданского права. В 1950 г. были изданы новые общие положения гражданского права7, которые, прежде всего, вводили изменения в области толкования, а также исполнения субъективных прав, отражающих идеологические основы государственного строя. Ввиду неприспособленности гражданского права к нуждам экономики социалистического характера, самые важные области правовых отношений в распределительно-приказной экономике были урегулированы актами более низкого ранга, чем закон, издаваемыми разными государственными органами. Внекодексные, иногда неконституционные правовые акты со временем стали «нормальным» явлением социалистического строя. Разрешение на такой порядок правового регулирования давало положение ст. 2 Гражданского кодекса, принятого в 1964 году. ${ }^{8}$ Из него вытекало, что в особых случаях, Совет министров или по его указанию другой орган высшей государственной власти мог урегулировать отношения гражданского оборота способом, отличающимся от положений кодекса. Такой специфический способ правообразования касался также положений Гражданского кодекса по характеру iuris cogentis. Положения iuris dispositivi изменялись произвольно. Тогда считалось, что если стороны могут по-другому формировать взаимоотношения, тогда тем более может это сделать вышестоящий орган. Если вспомнить, что в Гражданском кодексе находилось положение (ст. 384), уполномочивающее высшие органы государственной власти на издание обязательных условий договоров или

7 Ж3 № 34, поз. 311 (Dz.U. Nr 34, poz. 311).

8 ЖЗ № 16, поз. 93 (Dz.U. Nr 16, poz. 93). 
образцов договоров, тогда кодекс сразу открыл широкие рамки для нормотворческой деятельности в сфере обобществлённого оборота. В результате этого гражданский оборот регулировался в существенном объёме внекодексным положениям. кроме того, вводные положения Гражданского кодекса отменили действующие до его вступления в силу общие положения гражданского права, вещное право, Обязательственный кодекс, наследственное право. Был отменён также Торговый кодекс, за исключением положений касающихся открытого общества, общества с ограниченной ответственностью, а также акционерного общества и некоторых положений, связанных с функционированием этих обществ (положения о фирме, представительстве фирмы с правом подписи и реестре торговых фирм). Оставшаяся в силе часть положений Торгового кодекса пережила период социализма, главным образом, благодаря нуждам внешней торговли, которая выходила за границы лагеря государств т. наз. «демолюдов». кроме того, надо подчеркнуть, что в Польше не удалось полностью ликвидировать частную собственность, особенно это касается частной собственности на землю. Что очень характерно, земля в Польской Народной Республике никогда не была товаром. Оборот землёй находился под тщательным контролем и ограничивался применением с этой целью разных правовых и внеправовых средств. Подверглось колебанию соотношение между правомочиями и обязанностями, вытекающими из права собственности на землю, оставшуюся в частных руках. Продержались также мелкие частные предприниматели, несмотря на то, что в промышленности и торговле они составляли небольшой экономический потенциал. Идея предпринимательства, имеющая тесную связь с частной собственностью, не была в Польше совсем уничтожена, что благоприятствовало восстановлению рыночной экономики. Этот факт имел огромное значение, особенно сразу после перелома, вызванного изменением государственного строя, т. е. после 1989 г.

В условиях рыночной экономики фундаментальное значение играет автономность и равенство субъектов, принимающих участие в правовом обороте, отсутствие непосредственного принуждения со стороны государственных органов, право собственности и другие правовые институты, предоставляющие возможность пользования и распоряжения вещами или правами. Среди опор гражданского права находится свобода договоров, безопасность оборота и принцип истины. ${ }^{9}$ Эти ценности составляют основной свод принципов гражданского права. В литературе гражданского права в ПНР никогда не было согласованного свода принципов гражданского права. Ряд правовых конструкций в Гражданском кодексе 1964 г. решительно отходил по содержанию от классического образцов, ведущих происхождение от римского права. Такой от- 
ход произошел с правом собственности и принципом свободы договоров. Правовое понимание собственности получило совсем новое содержание, происходящее от идеологии, принятой Советским Союзом.

В ПНР были указаны категории права собственности. В конституции 1952 г. были записаны типы и формы собственности, т. е. определены направления, в соответствии с которыми государство должно было воздействовать на экономическую структуру общества. Пользуясь указаниями конституции, Гражданский кодекс осуществил деление собственности на общественную собственность (государственную, кооперативную и других организаций трудящихся), индивидуальную и личную. Различное отношение Гражданского кодекса к отдельным типам и формам собственности нашло своё выражение уже в общих положениях о собственности, т.е. в разном подходе правил толкования, которыми надо было руководствоваться в толковании и применении положений, касающихся отдельных видов собственности (общественной, индивидуальной, личной). Принимая во внимание первенство общественной собственности, Гражданский кодекс однозначно определил, что эта собственность находится под особой охраной права (ст. 129). Этот принцип осуществлялся с помощью специальных положений закона. кроме того, при введении в действие положений конституции Польской Народной Республики, касающихся обязанностей особой защиты общественной собственности, при второстепенном экономическом значении индивидуальной и личной собственности, установилось мнение о положительной обязанности охраны общественной собственности. Гражданский кодекс возложил на каждого гражданина обязанность охраны общественной собственности (ст. $137 \S 1$ ), отразившейся в судебной практике Государственного хозяйственного арбитража.

Особое место занимал принцип единства государственной социалистической собственности, выраженный в ст. 128 Гражданского кодекса, согласно которому социалистическая общенародная (государственная) собственность нераздельно принадлежала государству. Это должно было обеспечить преобладание этой формы общественной собственности над другой формой общественной собственности, т. е. над кооперативной собственностью. Единство государственной собственности должно было способствовать плановому руководству народным хозяйством. Содержание ст. 128 Гражданского кодекса было само по себе противоречиво и деформировало суть права собственности. Даже в публикациях, которые появились до 1989 года был сформу- 
лирован прямой вопрос: Является ли «общая общенародная собственность» «собственностью?». ${ }^{10}$ Следует добавить, что в сознании большинства польского общества общественная собственность как правовая и экономическая категория занимала второстепенное место, она воспринималась как «ничья собственность».

\section{3. Развитие правового регулирования отношений собственности в свете пе- ремен политического строя в Польше в 1989 г.}

Право собственности всегда привлекало внимание исследователей. Однако в истории бывают периоды особой заинтересованности этим правом. В Польше политический перелом в 1989 году положил начало процессу глубоких изменений политической системы. Началось строительство рыночной экономики. Для гражданского права это означало возвращение к первоначальным принципам, прежде всего, означало восстановление положения гражданского права как главного регулятора хозяйственных отношений.

В принципе модель политико-экономического строя и формы отношений собственности взаимно обусловлены, радикальные перемены политического строя связаны с глубокими преобразованиями в сфере собственности. ${ }^{11}$ Если мы считаем, что собственность является интердисциплинарной категорией, тогда перемены должны проходить не только на фоне юридическом или экономическом, но также в сфере социологических и психологических явлений и во многих других отраслях науки и практики, они касаются как отдельных граждан, так и общественных групп в масштабе всей страны.

После отхода от марксистской концепции собственности законодатель был вынужден вернуть форму собственности, адекватную новой рыночной экономике. С этой целью была начата правотворческая деятельность во многих сфеpax, касающихся отношений собственности и самого права собственности.

Реформа отношений собственности началась с изменения конституционных положений и положений Гражданского кодекса, так как именно в этих правовых актах находим основы дальнейшего регулирования отношений собственности. Закон от 29 декабря 1989 г. об изменении конституции Польской Народной Республики ${ }^{12}$, вместо марксистской концепции первенства государственной собственности вводит принцип равноправия всех хозяйственных

10 K. Brozi, L. Winiarski,, Czy „własność ogólnospołeczna” jest „własnością”? Studia Filozoficzne, 1980, Nr 7, s. 19.

11 M. Bednarek, Koncepcja własności w dobie transformacji ustrojowej w Polsce, Kwartalnik Prawa Prywatnego 1993, $\mathrm{Nr} 4$, s. 447, 448.

12 Ж3 № 75, поз. 444. Закон изменяет название на: «конституция Республики Польша». См. Также A. Lityński, O prawie i sądach początków Polski Ludowej, Białystok 1999, s. 240 (Dz.U. Nr 75, poz. 444 (Dz.U. Nr 75, poz. 444. Ustawą tą zmieniono tytuł na: "Konstytucja Rzeczypospolitej Polskiej". 
субъектов. Были отменены положения, связанные с действующей дифференциацией собственности, которые устанавливали привилегии для общественной собственности. Руководствуясь изменениями конституции, законодатель произвёл новеллизацию Гражданского кодекса, в 1990 г. отменил положения ст. 126-135, являющиеся последствием предыдущего конституционного регулирования права собственности, основанных на марксистской типизации. Из Гражданского кодекса были изъяты положения о субъектах обобществлённой экономики, ликвидирован ряд привилегий, существующих до сих пор на фоне гражданского материального и процессуального права, предусмотренных для субъектов, связанных с общественной собственности, и особенно государственной. ${ }^{13}$ Обобщая все вышесказанное, можно сказать, что основной целью этих законодательных нововведений было прекращение связей отдельными с субъективными привилегиями права собственности, с идеологизацией гражданско-правовых отношений и восстановление правовых инструментов, предоставляющих возможность обмена товаров и услуг на основе принципов рыночной экономики. Стоит вспомнить о введении в Гражданский кодекс принципа свободы договоров (ст. $\left.353^{1}\right)^{14}$, законного понятия предприятия в предметном значении (ст. $55^{1}$ ) и постепенном введении в жизнь положений Торгового кодекса. ${ }^{15}$ Что интересно, предметное понятие предприятия было введено в 1990 г., главным образом, для нужд приватизации, сегодня после корректировки его содержания в 2003 году оно находит применение в правовом обороте предприятий.

Среди действий, которые привели к преобразованиям политического строя, особенно следует отметить приватизации государственной собственности, иногда называемое процессом генерального «отхода от государственной» собственности. ${ }^{16} \mathrm{~B}$ частности, был принят принцип, что частная собственность должна стать основой общественно-политического строя в III Речи Посполитой. Опыт последних десятилетий отчётливо показал, что экономика, основанная на государственной собственности, обречена на неудачу, «(...) государство, всегда большой потребитель, всегда будет плохим производителем». ${ }^{17}$ Существуют многочисленные мнения о том, что государство, осуществляя хозяйственную деятельность, не может по своей природе принять принципов

13 Ж3 1990, № 55, поз. 321, 318 (Dz.U. Nr 55, poz. 321, 318).

14 См. Шире на эту тему: P. Machnikowski, (w:) E. Łętowska (red.), System prawa prywatnego. Prawo zobowiązań - część ogólna. Tom 5, Warszawa 2006, s. 416; M. Niedośpiał, Swoboda czynności prawnych, Bielsko-Biała 2004).

15 Сейчас действует закон от 15 сентября 2000 г. кодекс торговых обществ, Ж3 № 94, поз. 1037 с поздн. изм.(Obecnie obowiązuje ustawa z 15.09.2000 r. Kodeks spółek handlowych, Dz.U. Nr 94, poz. 1037 z późn. zmianami).

16 M. Bednarek, Koncepcja własności w dobie transformacji ustrojowej w Polsce, Kwartalnik Prawa Prywatnego 1993, Nr 4, s. 447, 448.

17 S.Z. Szyszkowski, Zagadnienie komercjalizacji przedsiębiorstw państwowych, Warszawa 1930, s. 15. 
функционирования частной экономики. ${ }^{18}$ Сегодня всё это многократно подтверждается выводами экономистов, юристов, социологов. После политикогосударственного перелома в 1989 году продолжались дискуссии на тему превосходства частной собственности над общественной. Теория права собственности говорит о том, что разные формы собственности дают начало разным экономическим стимулам, следовательно - приводят к разным экономическим результатам. По мнению Я. Титтенбруна форма собственности решает выбор направлений в деятельности экономических субъектов. ${ }^{19}$

В Польше с процессом приватизации связывали огромные надежды на восстановление рыночной экономики. как впоследствии оказалось, это был длительный и трудный период. кроме многих положительно воспринятых результатов, этот период принёс ряд явлений дисфункционального характера. ${ }^{20}$ Сегодня часто указывается на неправильную очерёдность упорядочения правовых отношений собственности в Польше после 1989 г. До начала процесса приватизации государственных предприятий, которые обладали государственной собственностью, надо было провести реприватизацию имущества, национализированного в течение нескольких лет после второй мировой войны. Это был бы один из существенных способов восстановления частной собственности. Трудно отказать в правоте таким точкам зрения. Некоторые посткоммунистические страны пошли таким путём. Это касается в особенности Германской Демократической Республики и Чехословакии. Приватизация в посткоммунистических странах оказалась очень сложным процессом. Ни одна научная теория не предвидела такого поворота в истории, поэтому трудно было найти образец поведения. Не всегда можно было предвидеть или определить следствия совершения пути «обратно к капитализму». ${ }^{21}$

Обычно обоснование приватизации простое: если мы хотим рыночную экономику, тогда надо приблизить структуру собственности хозяйства к такой, какая существует в развитых рыночных экономиках, это обозначает приватизацию доминирующей до сих пор государственной собственности. ${ }^{22} \mathrm{C}$ теоретической, а также практической точек зрения - это проблема сложная, требующая более широкого рассмотрения. Прежде всего, термин «приватизация» воспринимается неоднозначно.

\footnotetext{
18 A. Schatz, L'eutreprise governementale et son administration, Paris Grasset 1922, s. 16.

19 J. Tittenbrun, Teoria wolnodostępnej własności, Ruch Prawniczy Ekonomiczny i Socjologiczny 1996, Nr 2, s. 123 i n.).

20 T. Mróz, Funkcje spółek kapitałowych w procesie prywatyzacji przedsiębiorstw państwowych, Białystok 1999 S. 250 .

21 P. Jasiński, SJ., Z powrotem do kapitalizmu. Problemy przekształceń systemowych i własnościowych, Warszawa 1994, s. 10.

22 M. Iwanek, Niektóre problemy przekształceń własnościowych przedsiębiorstw w świetle ekonomii, (w:) M. Iwanek, A. Kwieciński (red.), Przekształcenia własnościowe a funkcjonowanie przedsiębiorstw (materiały konferencyjne), Warszawa 1992, s. 7 i 8.
} 
Часто приватизация понималась и связывалась только с происходящими переменами собственности, особенно с изменением правовой формы государственных предприятий и продажей частным лицам имущества, являющегося собственностью государства. Однако было признано, что независимо от определения того, что такое «приватизация», невозможно было свести смысл этого понятия только к изменению собственника, хотя по многим причинам эта проблема очень важна для всего процесса. Очень поверхностный исторический анализ общественно-экономических процессов позволяет отметить, что формально-правовой аспект является существенным (часто основным) элементом, условием изменения в экономическом поведении субъектов хозяйствования. Этот апект может быть гигантским шагом на пути общественно-экономических изменений, началом дальнейших процессов во всей экономике или в определённом её сегменте. Формально-правовая сторона здесь очень важна, однако это не единственный элемент приватизации. ${ }^{23}$ Этот процесс состоит из многих явлений и событий политического, экономического и социологического характера.

Рассматривая приватизацию, надо ответить на вопрос: под этим понятием мы понимаем приватизацию экономики или только приватизацию государственных предприятий?

Если примем во внимание первую интерпретацию, более широкую, то из неё вытекает, что речь идёт обо всех способах воздействия на рост и эффективность хозяйства, основанного на частной собственности. Если ограничимся ко второй, тогда в центре внимания остаются, главным образом, способы уменьшения той части публичного сектора, которая организована в форме государственных предприятий. Упрощённо можем сказать, что первый подход ориентирован на строительство, второй - главным образом, на демонтаж социалистической распределительно-приказной экономической системы.

Положения законов о приватизации ${ }^{24}$ экспонировали «техническую» процедурную сторону «отхода от государственной собственности» государственного предприятия. В них нет генеральной правовой конструкции понятия и содержания частной собственности.

Это в некоторой степени оправдано, так как идеей положений о приватизации не является создание теоретической конструкции частной собственности,

23 Cz. Żuławska, Niektóre prawne i ekonomiczne aspekty prywatyzacji, Państwo i Prawo 1991, Nr 2, s. 5.

24 Речь идёт прежде всего о: Ustawę z 13.07.1990 r. o prywatyzacji przedsiębiorstw państwowych, Dz.U. Nr 51, poz. 298, а также Ustawę z 30.08.1996 r. o komercjalizacji i prywatyzacji przedsiębiorstw państwowych, Dz.U. 118, Nr 561. См. также W.J. Katner, Komentarz do ustawy o komercjalizacji i prywatyzacji, Warszawa 2003 oraz W.J. Katner, Rozwiązania prawne i przebieg prywatyzacji w Polsce, (w:) Studia z prawa gospodarczego i handlowego. Księga pamiątkowa ku czci Profesora Stanisława Włodyki, Kraków 1996, s 216. 
но проведение процесса структурных перемен собственности в народном хозяйстве, основанном до сих пор на государственной собственности.

\section{4. Функциональная дифференциация собственности в условиях рыночной экономики}

В нынешних условиях функционирования общества и народного хозяйства нельзя защитить гипотезу, что преобразования собственности и строя вызвали возвращение к частной собственности в смысле универсальной модели собственности. Следует при этом добавить, что до сих пор нет законного определения понятия частной собственности, однако оно всё чаще появляется в законах и подзаконных нормативно-правовых актах. Появляются мнения, что в Польше можно говорить о формировании частной собственности как об отдельной правовой категории собственности. Нельзя не вспомнить об очень интересном мнении, высказанном С. Вуйцик, который подтвердил, что действующие положения не препятствуют выделению на почве legis late частной собственности как отдельной категории собственности. ${ }^{25}$ Автор признал, что частная собственность состоит из собственности на средства производства физических лиц, а также собственность юридических лиц, отличных от, чем государственных и коммунальных.

В сегодняшних условиях право собственности подвергается изменениям, если говорить о его конкретном содержании, урегулированном законоположениями. Эти изменения являются производной разных факторов, чаще всего экономических, технологических, экологических. Это не противоречит общему тезису, что в понятии собственности находится неизменный элемент, определяемый правовой наукой как «прочная и вечная идея собственности» или как «стержень собственности». Эта «прочная и вечная идея собственности» понимается как «предписание конкретному лицу или группе лиц презумпции исключительного пользования и распоряжения вещами или другими нематериальными благами». ${ }^{26}$ конституция Республики Польша ${ }^{27}$ отмечает прочный и нерушимый элемент собственности в ст. 64, абзац 3 , в котором говорится о том, что «право собственности может быть ограничено только на основании закона и только в тех пределах, в которых он не противоречит сущности права собственности». кроме того, ст. 64 абзац 1 и 2 конституции подтверждает, что «каждый может иметь право собственности, другие имущественные права, а также право наследования; собственность, другие имущест-

\footnotetext{
25 S. Wójcik, Problem pojęcia „własność prywatna” w III Rzeczypospolitej, Rejent 1991, Nr 7-8, s. 14.

26 W. Pańko, O prawie własności i jego współczesnych funkcjach, Katowice 1984, s. 15.

27 ЖЗ № 78, поз. 483 (Dz.U. Nr 78, poz. 483).
} 
венные права, а также право наследования пользуются равной для всех правовой защитой». ${ }^{28}$

По мнению А. Стельмаховского перелом 1989 года принёс существенную переоценку в области собственности. ${ }^{29}$ Автор подчёркивает, что на первый план выдвигается деление на собственность частную и собственность публичную. Это, прежде всего, функциональное деление, хотя такое деление играет здесь особенную роль. Публичная собственность осуществляется теми субъектами права, которые должны решать к публичным задачи, это - прежде всего Государство и территориальное самоуправление.

В соответствии со ст. 20 конституции социальное рыночное хозяйство основано на свободе хозяйственной деятельности, частной собственности, тем самым появление публичной собственности в хозяйственном обороте должно восприниматься как исключение.

Учитывая функциональное назначение собственности, в рамках частной собственности различаем:

- промышленно-торговую собственность,

- интеллектуальную собственность,

- сельскохозяйственную собственность,

- собственность жилищных фондов,

- собственность на леса,

- собственность на горные выработки.

Применяя аналогичный критерий классификации собственности, можем констатировать, что публичная собственность охватывает:

- часть государственной собственности, используемой в общественно полезных публичных целях,

- преобладающую часть коммунальной собственности, используемую в тех же целях,

- собственность тех юридических лиц, которые связваны с реализацией общественно полезных заданий (напр., Национальный Банк Польши, Учреждение социального страхования). ${ }^{30}$

Стоит также отметить, что при применении функционального критерия, границы между публичной и частной собственностью не всегда бывают чёт-

28 См. Шире T. Dybowski, Własność w przepisach konstytucyjnych wedle stanu obowiązywania w 1996 r., (w:) Konstytucja i gwarancje jej przestrzegania. Księga pamiątkowa ku czci prof. Janiny Zakrzewskiej, Warszawa 1996, s. 310.

29 A. Stelmachowski, Zarys teorii prawa cywilnego, Warszawa 1989, s. 187; A. Doliwa, Prawo rzeczowe, Warszawa 2010, s. 26 и след.

30 A. Stelmachowski, Zarys teorii prawa cywilnego, Warszawa 1989, s. 189. 
кими. К примеру, больница, работающая на основе частной собственности, исполняет функции публичного характера. Пахотные земли, практически являющиеся государственной собственностью, переданные в многолетнюю аренду, на это время теряют функциональные черты, характеризующие публичную собственность.

\section{Подведение итогов}

Действующий с 1 января 1965 г. Гражданский кодекс является первой кодификацией гражданского права в Польше. Однозначно можем признать, что это основа частного права в Польше. Это очень молодая кодификация по сравнению с законами, регулирующими частное право в других европейских странах. Причины некоторого замедления развития частного права в Польше известны и очевидны. Потеря государственности в конце XVIII века, продолжающаяся почти 150 лет, означала приостановление законодательной деятельности. Несмотря на то, что в период ПНР в Гражданском кодексе нашлись многие институты характерные для социалистического права, отвечающие основам этого строя, однако он в принципе сохранил все традиционные институты гражданского права. ${ }^{31}$ Изменения многих положений Гражданского кодекса оказались бы невозможными без преобразований собственности, осуществляемых в процессе приватизации, особенно приватизации государственных предприятий, к которым принадлежал почти весь экономический потенциал Польши.

Сегодня, после многих новеллизаций Гражданского кодекса, польский законодатель, в отличие от других законодателей социалистических государств, принял принцип единства гражданского права, подверг кодифицированному урегулированию также сферу профессионального оборота.

Основные изменения Гражданского кодекса произошли в 1989 - 1990 гг. Закон от 31 января 1989 г. об изменении закона Гражданский кодекс ${ }^{32}$ отменяет принцип единства государственной собственности в ст. 128 кодекса. Затем закон от 28 июля 1990 г. об изменении закона Гражданский кодекс ${ }^{33}$ исключает положения, которые вводили типы и формы собственности, при сохранении классического определения собственности в ст. 140 кодекса, согласно которой в пределах определённых законом и принципом социального сосуществования собственник может, за исключением других лиц, пользоваться вещью согласно социально-экономическому предназначению своего права, в особенности пользоваться выгодами и другими доходами. В тех же пределах может распо-

\footnotetext{
31 M. Pyziak-Szafnicka (red.), Kodeks cywilny. Część ogólna, Warszawa 2009, s. 16.

32 Ж3 № 3, поз. 11(Dz.U. Nr 3, poz. 11).

33 Ж3 № 55, поз. 321 (Dz.U. Nr 55, poz. 321).
} 
ряжаться вещью. ${ }^{34}$ Стоит также обратить внимание на то, что после 1989 г. чётко изменилось толкование понятий «принципы социального сосуществования» и «социально-экономическое назначение права». Произошёл отход от строевой коннотации этих понятий. Постепенно они заменялись оговоркой о правильности, справедливости и хороших обычаях (напр., ст. $385^{1}$ ).

Изменения Гражданского кодекса совпали во времени с возобновлением после пятидесяти лет территориального самоуправления, а также началом процесса приватизации и его правового урегулирования. Закон от 1990 г. вводит также много других изменений, напр., восстанавливает традиционную форму давности имущественных притязаний, либеризует принципы прекращения общей собственности и наследования земельных участков крестьянских (фермерских) хозяйств, вводит также понятия предприятия и земледельческого хозяйства. Глубокий экономический кризис, сопутствующий падению социалистического строя, вызвал восстановление известной Обязательственному кодексу клаузулы rebus sic stantibus. По той же причине допускалось применение клаузул валоризации, а также судебной валоризации исполнений по денежному обязательству. В большинстве своём действия законодателя заключались в восстановлении классических институтов гражданского права, а также исключении институтов типичных социалистическому строю. В таком положении мы можем говорить не о реформе, но прежде всего о возобновлении, восстановлении основ гражданского права. Дальнейшие изменения Гражданского кодекса не имели уже такого принципиального характера, как изменения произошедшие в 1989-1990 гг., хотя были значимыми для гражданско-правового оборота в рыночной экономике.

34 Шире на тему проблем частного права см. E. Gniewek (red.), Kodeks cywilny. Komentarz, wyd. 4, Warszawa 2011, s. 293 i nast а также K. Pietrzykowski (red.), Kodeks cywilny tom I. Komentarz do art. 1-44910, wyd. 6, Warszawa 2011, s. 554 и след. 


\section{RESTORING THE FOUNDATIONS OF CIVIL LAW IN POLAND IN 1989 (IN PARTICULAR WITH RESPECT TO PROPERTY RIGHTS)}

Civil law in Poland has undergone many changes whereas its content was subject to various experiments. Despite this, from the perspective of over twenty years that have elapsed since 1989, it can be ascertained that the civil law contains a certain nucleus of values that has resisted the pressure exerted by the socialist doctrine on the one hand, and allowed to preserve elementary features of civil law in 1944-1989 on the other. Nevertheless, many classic legal constructions were either eliminated or deformed by the ideology of the state's socialist system. Thus, the time of system transformation in Poland that commenced after 1989, has also become the period of reconstruction of many classic institutions and values being axiological in nature that justify private law norms.

Key words:

The state's political system vs. the law, market economy, private property. 